\title{
CONSTRUINDO PONTES: DIÁLOGOS A PARTIR DO/COM O FEMINISMO NEGRO'
}

\section{RESUMO}

Este artigo passa em revista o pensamento de diversas teóricas do feminismo negro, especialmente as estadunidenses, consideradas centrais nesta vertente do feminismo, como Sojourner Truth (1852), Angela Davis (2016), Audre Lorde (1984) e bell hooks (1981). Discute-se desde a origem da vertente, a partir do questionamento de Truth (1852) de "E eu não sou uma mulher?", passando pelas suas bases conceituais com Collins (2000a), até as contribuições mais recentes do feminismo negro britânico e sua relação com o pós-colonialismo, com Carby (1982) e Pramar (1990). Evidencia-se, desse modo, a multiplicidade de ideias dentro do feminismo negro, demonstrando sua complexidade em diferentes contextos socioculturais.

Palavras-chave: Feminismo Negro. Gênero e raça. Lutas sociais.

\section{RESUMEN}

Este artículo revisa el pensamiento de diversas teóricas del feminismo negro, en especial las estadunidenses, consideradas centrales en esta vertiente del feminismo, como Sojourner Truth (1852), Angela Davis (2016), Audre Lorde (1984) e bell hooks (1981). Se discute desde el origen de la vertiente, partiendo del cuestionamiento de Truth (1852) de “¿Acaso no soy mujer?”, pasando por sus bases conceptuales con Collins (2000a), hasta las contribuciones más recientes del feminismo negro británico y su relación con el post colonialismo, con Carby (1982) y Pramar (1990). Se evidencia, de este modo, la multiplicidad de ideas dentro del feminismo negro, demostrando su complejidad en diferentes contextos socio-culturales.

Palabras-clave: Feminismo Negro. Género y raza. Luchas sociales.

Nós acreditamos que a política da sexualidade sob este sistema patriarcal se assenhora das vidas das mulheres negras tanto como a política de classe e raça. Também encontramos difícil separar a opressão racial da classista e da sexual porque em nossas vidas as três são uma experiência simultânea.

(The Combahee River Collective, 2012)

\footnotetext{
1 Este texto, originalmente publicado em espanhol sob o título "Indroducción. Construyendo puentes: em diálogo desde/con el feminismo negro", faz parte da Antologia de textos Feminismos negros: una antologia, organizada por Mercedes Jabardo em 2012. Agradecemos à autora pela concessão de direitos autorais deste texto. Tradução em língua portuguesa de Liliam Ramos da Silva e Adriana Kerchner da Silva (UFRGS).
}

Mercedes Jabardo Velasco

Professora de Antropologia Social, Universidade Miguel Hernández de Elche (Alicante, Espanha). 
O feminismo negro possui as características dos movimentos que estão em processo de construção de seu programa de luta e de emancipação a partir de diversas e superpostas estruturas de dominação. Inclusive conflitivas, por vezes. Falar de gênero e de "raça" como elementos de desigualdade é, em certo sentido, reducionista se não estiver demarcado nas condições em que ambos os critérios emergiram como veículos de opressão. O movimento feminista negro surgiu na confluência (e tensão) entre dois movimentos: o abolicionismo e o sufragismo, em uma difícil intersecção. Mesmo tendo uma presença relevante em ambos, a combinação de racismo e sexismo terminou excluindo as mulheres negras dos dois. Tal fato não paralisou seu impulso emancipador, muito pelo contrário. As feministas negras foram, desde o princípio, extraordinariamente lúcidas na hora de se posicionarem e fortes na hora de estabelecerem alianças: com os homens de sua própria "raça" nas antigas comunidades de escravizados, com as mulheres brancas na luta pelo sufrágio feminino e, sobretudo, com todas as mulheres negras quando o racismo contaminou o movimento sufragista estadunidense e quando a emancipação incorporou as diferenças de gênero nas comunidades negras.

Aquilo que desde o feminismo pós-moderno tem sido traduzido por teoria da interseccionalidade está na base genealógica do feminismo negro afroestadunidense. ${ }^{3}$ Remontamos ao discurso "E não sou eu uma mulher?" de Sojourner Truth na Convenção dos Direitos da Mulher em Akron de 1852 e à explosão de escritas de mulheres negras na década de 1890 na qual, além dos textos de Ida Wells, foram produzidas obras como $A$ voice from the South by a Black Women from the South de Anna Julia Couper (1982) e, posteriormente, A Coloured Women in a White World de Mary Church Terrel (1940) (Ritzer, 2003).

\section{Pioneiras do feminismo negro}

Destacar duas entre centenas de vozes resgatadas nesse período não é uma tarefa fácil. No entanto, Ida Wells e Sojourner Truth são sem dúvida duas das mais significativas. E o são tanto por suas posições teóricas (no caso de Wells) quanto pela coragem e lucidez de uma mulher iletrada (como Sojourner Truth). Elas assentaram as bases do que seria o pensamento feminista negro (a clara ligação da reflexão teórica às estratégias de mobilização) e também são o reflexo da forma coletiva de produção do conhecimento do feminismo negro. Diferentemente do feminismo branco, que tem seu momento fundacional no Iluminismo e reproduz a racionalidade do

2 No Brasil, há discussões sobre a utilização dos termos "raça" e "etnia". Enquanto "raça" se referiria ao fenótipo, "etnia" contemplaria características socioculturais. No texto-fonte, a autora emprega a palavra raza (raça) sempre entre aspas. Para preservar a ideia controversa que o conceito apresenta, optamos por manter o termo "raça" entre aspas. (Nota das tradutoras)

3 Como latino-americanistas e pesquisadoras de literatura afro-americana que contempla a produção de autoria negra na América enquanto continente, traduzimos afro-americano (e suas variáveis de gênero e número) por afro-estadunidense na intenção de marcar a nacionalidade em questão. (Nota das tradutoras) 
pensamento ilustrado, o feminismo negro surge em um contexto escravista. Nesta reflexão, pretendemos romper com a construção individual do pensamento filosófico ilustrado, apostando na inclusão de distintos saberes, lógicas e atrizes sociais.

Se tivéssemos que fazer referência a um "texto" fundacional do feminismo negro, seria o discurso “E não sou eu uma mulher?" de Sojourner Truth na Convenção dos Direitos da Mulher em Akron em 1852. Encontramos nele algumas das características que permitem compreender o caráter contra-hegemônico desse movimento. Em primeiro lugar, a oralidade do relato frente à racionalidade da escrita dos textos fundacionais do feminismo branco. A oralidade, como também a oratória aprendida e praticada nos púlpitos das igrejas. Ambas foram ferramentas de resistência dos grupos subalternos. Em segundo lugar, o próprio caráter da oradora: Sojourner Truth foi a primeira de uma importante leva de intelectuais negras que, sem o apoio de uma obra escrita, conectaram os interesses e as lutas das mulheres negras (COLLINS, 200oa). Em terceiro lugar, por ser um texto produzido em situação de colonialidade. Nesse contexto, com uma linguagem própria que não se vê refletida no espelho imposto, Sojourner Truth desconstrói a categoria (hegemônica) de mulher - uma categoria negada a ela - reivindicando sua própria identidade enquanto mulher. A intersecção da "raça" com o gênero, que fez com que o sistema hegemônico construísse a ideia de mulheres negras como não mulheres, reaparece no discurso de Sojourner de forma inclusiva. Por trás do seu "E não sou eu uma mulher?", por trás das lutas de outras ex-escravizadas como Harriet Jacobs, aparece um desejo que luta por ressignificar o termo mulher. Sua aspiração era serem livres, não somente da opressão racista, mas também da dominação sexista.

As contribuições de Sojourner Truth ao movimento sufragista (invisibilizadas pelo feminismo branco) e ao pensamento feminista negro (resgatadas nos anos 80 do século XX) têm sido amplamente difundidas (inclusive em língua espanhola) nas últimas décadas. Estamos orgulhosas de que esse texto fundacional abra a presente antologia.

$\mathrm{Na}$ década de 1890 , quando aparecem obras de referência das primeiras acadêmicas negras, a distância entre mulheres negras e mulheres brancas, que se tornara visível dentro do movimento sufragista, era ainda mais profunda. A abolição da escravidão, que a comunidade negra recebeu com esperança, somente transformou a superfície da sociedade de castas que dividia as pessoas entre amos e escravizados. Logo, a discriminação racista substituiu a escravidão como "moderno" critério de desigualdade. Em 1894, já haviam sido estabelecidos a privação do voto das pessoas negras do Sul, o sistema jurídico segregacionista e a vigência da lei Lynch (Wells, 2012). Inclusive, algumas sufragistas assumiram proposições eugenistas e a ideologia da domesticidade. ${ }^{4}$ As palavras de Belle Kerney, retomadas por Angela Davis, são um fiel reflexo do clima em que se respirava:

4 Angela Davis resgata as palavras de Elizabeth Cady Station, uma das pioneiras do sufragismo estadunidense: "Quando o sr. Downing me faz a pergunta: você está disposta a ver o homem de cor obter o direito ao voto antes das mulheres? eu digo que não; eu não confiaria a ele meus direitos; desvalorizado, oprimido, ele poderia ser mais despótico do que nossos governantes anglo-saxões já são. Se as mulheres ainda devem ser representadas pelos homens, então eu digo: deixemos apenas o tipo mais elevado de masculinidade assumir o leme do Estado" (Davis, 2016, p. 100).- 
A concessão do direito de voto às mulheres garantiria a imediata e duradoura supremacia branca, alcançada de modo honesto; pois, como indicam dados oficiais inquestionáveis, "em todos os estados do Sul, com exceção de um, há mais mulheres instruídas do que todos os eleitores analfabetos, brancos e negros, nativos e estrangeiros, somados" (Davis, 2016, p. 139).

Assim se apresentava o sufrágio feminino branco como o meio mais adequado para alcançar a supremacia racial. Deixando de lado aspectos tais como a solidariedade, a luta pelos direitos das mulheres ou a igualdade política, o incipiente movimento feminista se converteu em um mero baluarte da superioridade racial das pessoas brancas. O movimento sufragista ficou fatalmente impregnado de racismo, o que não somente abriria uma brecha irreparável no feminismo estadunidense (feminismo branco versus feminismo negro), mas também se transformaria em um instrumento (a mais) no processo de objetificação da mulher negra. Ao assumirem para si mesmas o papel de "guardiãs e protetoras naturais do lar", ao reivindicar o voto feminino a partir de seu papel de mães dos futuros cidadãos, as mulheres brancas excluíam as mulheres negras do voto, da categoria de mãe e, portanto, de mulher.

$O$ primeiro clube de mulheres negras foi organizado em resposta à desenfreada onda de linchamentos e ao abuso sexual indiscriminado que elas sofriam. Ida B. Wells foi uma de suas fundadoras; ambas as questões eram ao mesmo tempo objeto de suas pesquisas e motor de suas reivindicações. Tanto Wells quanto Anna Julia Cooper, outra socióloga afro-estadunidense, em posições sociais diferentes, se inspiraram conscientemente em suas experiências de vida como mulheres afro-estadunidenses para desenvolver uma consciência sistemática da sociedade e das relações sociais. ${ }^{5}$ Não são, nesse sentido, muito diferentes de outros pensadores que surgiram entre os subalternos.

Ida Wells, célebreintelectual, jornalista eativista negra, canalizou suas energias na luta contra os linchamentos sistemáticos que sofria a população negra depois de constatar que as vítimas não eram culpadas pelos crimes dos quais eram acusadas (na maioria das vezes, pelo ato de estupro). Ela chegou a essa conclusão de forma dramaticamente fortuita, quando três de seus amigos mais íntimos foram linchados, acusados desse delito. Essa circunstância a levou a investigar de forma sistemática todos os atos de linchamento cometidos no Sul, utilizando uma metodologia que só recentemente teve reconhecimento científico. Utilizou as únicas fontes que existiam - as do opressor - para, a partir delas, descobrir questões subjacentes à dominação. Partindo dos relatos dos linchamentos, escritos em jornais de pessoas brancas, analisou as fontes secundárias do Chicago Tribune e fez trabalho de campo logo após os atos arbitrários. Elaborou e publicou estatísticas arrasadoras: mostrou que entre 1880 e 1891 em torno de 100 negros foram linchados; que no ano de 1892, quando mataram seus amigos, outros 160 homens também foram linchados, a maioria por

5 Assim destacava o eminente sociólogo Ritzer (2005) em sua mais recente recuperação das sociólogas afro-estadunidenses. 
assassinato (58) e por estupro (46). Denunciou que os atos eram utilizados para conter a possível ascensão social da população negra no Sul. Apontando as lógicas a partir das quais se denunciava como estupro qualquer contato (às vezes, meramente verbal) entre um homem negro e uma mulher branca, Wells introduziu um dos temas que seria central no feminismo negro: a forma como a interseccionalidade entre "raça" e gênero constrói de maneira desigual a sexualidade da população branca e da população negra. Fez isso destacando os mecanismos através dos quais são demonizadas as relações raciais entre homens negros e mulheres brancas - usando o termo estupro para qualquer tipo de contato ou aproximação entre eles - e a maneira como é naturalizada qualquer forma de agressão sexual (estupro) de homens brancos a mulheres negras.

Angela Davis retoma esse assunto:

O nó histórico que ata as mulheres negras (sistematicamente abusadas e violadas por homens brancos) aos homens negros (mutilados e assassinados devido à manipulação racista das acusações de estupro) apenas começou a ser reconhecido de modo significativo. Sempre que as mulheres negras desafiaram o estupro, elas expuseram simultaneamente o uso das acusações falsas de estupro enquanto arma mortal do racismo contra seus companheiros (Davis, 2016, p. 189).

A aliança racial entre homens e mulheres negras crescia paralelamente à grande brecha que se abriu no movimento sufragista. Os clubes de mulheres negras foram extintos e até mesmo nas grandes passeatas pelo sufrágio feminino as líderes (brancas) do movimento assumiram a política segregacionista obrigando as mulheres negras a caminharem separadamente. Essa convivência constante com o racismo, incluindo a das intelectuais negras dos grupos abastados, serviu, desde o princípio, como nexo de união com as mulheres negras da classe trabalhadora, criando assim um vínculo interclassista que vem diferenciando o feminismo negro do feminismo branco de origem burguesa e que, além disso, está na base da sororidade [sisterhood] que reclamam para si as teóricas do feminismo negro.

\section{Bases conceituais do feminismo negro}

Enquanto o feminismo moderno/ilustrado se desenvolveu a partir de Simone de Beauvoir e sua afirmação "Não se nasce mulher, torna-se mulher", os discursos de gênero no feminismo negro partem de uma negação, de uma exclusão, de uma interrogação, o que bell hooks (1981) retoma de Sojourner Truth em um dos primeiros textos do pensamento feminista negro: "E não sou eu uma mulher?"

Não é um título escolhido ao acaso. A interrogação resgatada por bell hooks é a expressão de um sentimento coletivo que responde de forma irônica às teorias feministas de gênero surgidas da tese de Simone de Beauvoir, teorias que serviram 
para compreender que a identidade coletiva e pessoal é reconstruída socialmente de maneira precária e constante (Haraway, 1995). A partir do feminismo negro, a identidade da mulher é simultaneamente reclamada e reconstruída. Frente aos exercícios "construtivistas" do feminismo branco, o feminismo negro parte de uma não categoria (não mulher). A única estratégia possível na negação é um exercício de desconstrução. Destruir a negação na qual as mulheres negras foram excluídas da categoria de mulheres para assim avançarem, repensarem-se e reconstruíremse em outras categorias; re-conhecerem as imagens de não mulher como estratégia de hegemonia e dotarem-se das ferramentas adequadas para sua revelação e sua superação. Ferramentas que, nas palavras de Audre Lorde (1984), não poderão ser as ferramentas do amo: "As ferramentas do amo nunca vão desmantelar a casa-grande. Talvez nos permitam obter uma vitória passageira seguindo as regras do jogo, porém nunca nos valerão para efetuar uma autêntica mudança"6. Para deixarem de ser constituídas como objetos e pensarem-se enquanto sujeitos, tiveram que tomar a palavra, recuperar a voz e gerar um novo discurso. Definitivamente, criar uma nova epistemologia.

\section{O discurso duplo dos grupos dominados. Patricia Hill Collins}

Os primeiros textos de teoria feminista negra foram publicados nos Estados Unidos na década de 80 do século XX quando se forjava o que seria denominado a segunda onda do feminismo. Desde diferentes enfoques teórico-práticos - que tiveram uma leitura em termos de feminismo liberal, feminismo radical e feminismo socialista -, foram se ramificando os eixos teórico-políticos do que foi o movimento feminista da segunda metade do século XX, cujas sequelas seguem presentes nos discursos do feminismo hegemônico. Sánchez, em uma interessante revisão do(s) feminismo(s) na Espanha, faz uma articulação em torno de dois grandes temas: o primeiro, representado no lema "o pessoal é político", queria chamar a atenção para os conflitos e problemas que as mulheres enfrentam no âmbito privado; o segundo estruturaria a análise das causas da opressão, na qual o conceito de patriarcado desempenharia um papel fundamental, reformulado por algumas autoras segundo o sistema de sexo-gênero (Álvarez, 2001; Sánchez, 2001). Foi precisamente o sistema de sexo-gênero o que as feministas negras primeiro puseram em questão. Uma das premissas centrais desse sistema, tal e qual o formulou Rubin em um profícuo artigo em 1975, explica a complementaridade dos sexos e a opressão das mulheres pelos homens através do intercâmbio das mulheres dentro do sistema de parentesco.

6 No texto de partida: "Las herramientas del amo nunca desmontan la casa del amo. Quizá nos permitan obtener una victoria pasajera siguiendo sus reglas del juego, pero nunca nos valdrán para efectuar un auténtico cambio" (tradução nossa). É possível acessar à tradução completa do texto no par de línguas inglês-português realizada por Tatiana Nascimento em <https://www.academia.edu/11277332/ LORDE_Audre_-_As_ferramentas_do_mestre_nunca_v\%C3\%A30_desmantelar_a_casa-grande>, acessado em 10.mar.2019 
Hazel Carby (1987), Aída Hurtado (1989) e Hortense J. Spillers (1987), entre outras, questionaram a universalidade desse princípio. Elas se perguntaram: o que ocorre quando as mulheres não se encontram nas mesmas posições com relação à instituição do parentesco? O que ocorre com a ideia de gênero se grupos inteiros de homens e mulheres estão situados juntos, fora da instituição de parentesco, mas relacionados com a instituição de parentesco de um grupo dominante? E as três voltaram ao período da escravidão de onde, através de uma análise de corte historicista, mostraram como as mulheres negras não foram inseridas na sociedade estadunidense da mesma maneira que as mulheres brancas. Não foram as únicas. Os eixos teórico-práticos foram amplamente contestados por parte das feministas negras (Davis, 2016; Hull, Bell Scott, Smith, 1982; hooks, 1981, 1984). O que elas denunciavam era o próprio conceito de gênero, na medida em que fazia parte do sistema de relações hierárquicas de "raça”. Com a denúncia, começaram a escutar a sua própria voz, uma voz que havia estado obscurecida em um sistema de dominação que havia sido construído com as ferramentas dos grupos hegemônicos. Assim grita bell hooks:

Meu desejo de encontrar fontes que pudessem explicar a experiência negra (especialmente minha presunção de que os livros escritos por brancos poderiam conter tal explicação) é precisamente um reflexo da socialização dos grupos oprimidos e explorados em uma cultura de dominação. Nós aprendemos que não temos poder para definir nossa própria realidade ou para transformar as estruturas opressivas. Nós aprendemos a buscar naquelas capacitadas pelos sistemas de dominação, que nos ferem e nos são daninhas; procuramos ser liberadas e nunca conseguimos isso. Para nós, é necessário fazer o trabalho por nós mesmas se quisermos conhecer mais sobre nossa experiência, se quisermos ver essa experiência desde perspectivas inconformadas com a dominação (hooks, 1984, tradução nossa).

É preciso sair, portanto, das lógicas do discurso da dominação, afastar-se das formas que já foram pensadas. Para o feminismo negro, a geração de pensamento passava por um exercício de desconstrução e reconstrução. Nessa tarefa, a obra de Patricia Hill Collins tem um grande protagonismo. Em primeiro lugar, por seus aportes no campo da epistemologia, naquilo que ela estabelece como terceira via (entre as ideologias científicas da objetividade e os relativismos) e que faz referência a uma epistemologia alternativa que se sustenta na conexão entre conhecimento, consciência e políticas de empoderamento:

1. Na medida em que se constrói a partir da experiência vivida e não de uma posição teoricamente "objetiva", o conhecimento se desenvolve dialogicamente. Diante da linguagem objetiva e distante de outras formas de aproximação do conhecimento, nas epistemologias alternativas a autora é central e está 
presente no texto. Na epistemologia feminista negra, a história é contada e preservada em forma de narrativa e não de uma posição analítica.

2. A questão ética é colocada no centro da produção de conhecimento com o reconhecimento de que todo o pensamento está carregado de valor. Não cabe, portanto, uma distância objetiva com relação à realidade investigada, nem a ruptura binária entre intelecto e emoção que rege a perspectiva eurocêntrica. Pelo contrário, o conhecimento deverá ser testado pela presença de empatia e emoções.

3. A epistemologia feminista negra requer um acerto de contas pessoal. $\mathrm{O}$ pesquisador e a pesquisadora não estão separados, distanciados da verdade. A forma de produzir conhecimento dos grupos subjugados se dá em um sistema de conhecimento preexistente onde toda informação encontra sua existência e "verdade", e onde sua própria forma de produzir conhecimento "gera" verdade. Por isso tem uma maior carga de responsabilidade moral sobre ele.

Em segundo lugar, por suas contribuições ao pensamento feminista negro em particular e ao feminismo no geral. Todo o essencial está sistematizado em um livro escrito em 1990 e que se transformou em um clássico do pensamento feminista negro: Black Feminist Thought: Knowledge, Consciousness and the Politics of Empowerment. O capítulo que retiramos desse livro para a presente antologia sintetiza as características-chave. Com respeito à epistemologia alternativa, Collins defendia que epistemologia e conhecimento não são separáveis, tampouco alheios aos valores políticos nem às crenças individuais. A forma como nos aproximamos do conhecimento e o próprio conhecimento têm um significado em termos de empoderamento. Conhecimento, (auto)consciência e empoderamento são termos que aparecem constantemente interrelacionados em seu pensamento. "Escrevi Black Feminist Thought com o fim de ajudar no empoderamento das mulheres afroestadunidenses", escreveu Collins (20oob) no prefácio da segunda edição de seu livro. "Eu sabia que uma mulher negra, ao experimentar uma mudança de consciência com relação à sua própria vida, pode se empoderar". Hill Collins interrelacionava pensamento feminista negro e empoderamento em torno de três eixos.

No plano teórico, ela redefine o conceito de opressão em termos de interseccionalidade incorporando o que denomina "matriz de dominação"7 e adota a "teoria do ponto de vista" para caracterizar as bases do pensamento feminista negro,

7 A matriz de dominação faz referência à organização total de poder em uma sociedade. Há duas características em qualquer matriz: 1) cada matriz de dominação tem uma particular disposição dos sistemas de intersecção da opressão; e 2) a intersecção dos sistemas de opressão está especificamente organizada através de quatro domínios de poder interrelacionados: estrutural/disciplinário/ hegemônico/interpessoal. A intersecção de vetores de opressão e de privilégio cria variações tanto nas formas quanto na intensidade na qual as pessoas experimentam a opressão (Collins, 20oob, p. 299, tradução nossa). 
enfatizando a perspectiva das mulheres negras sobre sua própria opressão. Tudo isso gera uma tensão entre as mudanças coletivas e as experiências individuais que Collins resolve a partir de um duplo posicionamento: negando a possibilidade de um ponto de vista homogêneo e estabelecendo a formação de um ponto de vista coletivo.

Da mesma forma, mostra a articulação entre conhecimento e empoderamento. Como acontecia no movimento de mulheres brancas, no feminismo negro a crescente sensibilidade da diversidade no que é comum se conecta com a diversidade nas formas de ativismo que, no caso das mulheres negras, reverbera na criação de espaços sociais onde as mulheres falam por muito tempo. Collins identifica no texto três desses espaços sociais: a) o das relações das mulheres negras entre si; b) a tradição das cantoras de blues e c) as teóricas afro-estadunidenses. Enquanto que o primeiro espaço está fixado no dia a dia das mulheres negras, os dois últimos são os que historicamente deram voz às mulheres que não tinham voz. A importância desses espaços se estabelece na medida em que proporcionam oportunidades para a autoidentificação, que é o primeiro passo para o empoderamento. Se um grupo não se define a si mesmo, então será definido por e em benefício de outros.

Collins também situa a luta pela autoidentificação das mulheres negras enquanto coletivo de luta em um diálogo entre ação e pensamento. "Mudanças no pensamento" - afirma - "podem alterar condutas e as condutas alteradas podem produzir mudanças no pensamento". Ela vê essa mudança como um processo de rearticulação, mais que de criação de consciência, entendendo a rearticulação como um veículo para re-expressar uma tomada de consciência que já aparece nas ruas com uma certa frequência.

É difícil apontar brevemente as contribuições de Patricia Hill Collins não somente com relação à epistemologia feminista negra ou a dos grupos subjugados como também à teoria social geral. Apresentar a teoria e a prática de Collins como um solilóquio afrocentrado obscureceria a implicação teórica de seus aportes. De fato, Collins trata de colocar as mulheres negras estadunidenses no centro de suas análises. No entanto, ela faz isso sem privilegiar essas experiências. Para concluir com suas próprias palavras:

Apesar do enorme potencial das mulheres afro-estadunidenses para iluminar a matriz de dominação, o ponto de vista delas é somente um ângulo de visão. $\mathrm{O}$ pensamento feminista negro representa uma perspectiva parcial. A matriz de dominação geral acolhe múltiplos grupos, cada um com variadas experiências de provações e de privilégios quegeram perspectivas correspondentes parciais, conhecimentos situados e, para grupos subordinados claramente identificáveis, conhecimentos subjugados [...] Esse enfoque feminista afrocêntrico permite às mulheres afroestadunidenses levar o ponto de vista das mulheres negras a diálogos epistemológicos mais amplos relativos à matriz de dominação. Eventualmente, tais diálogos podem levar a um ponto 
no qual todas as pessoas apreendam o core em outra experiência. (Collins, 200ob, p. 229, tradução nossa)

\section{Os rostos da resistência. As mulheres negras do blues de Angela Davis}

Sob a máscara, no gueto da comunidade das mulheres negras, na sua família, e mais importante, na sua psique, há e sempre houve outro mundo, um mundo no qual ela opera - às vezes com vergonha, mas frequentemente com verdadeiro deleite - fazendo o que fazem as mulheres negras "normais".

(O’Neale, 1986, p. 139)

Estamos enraizadas na linguagem, casadas, nosso ser são as palavras. A linguagem é também um lugar de combate. O combate dos oprimidos em relação à linguagem para nos recuperarmos a nós mesmas - para reescrever, reconciliar, renovar. Nossas palavras não carecem de importância. São um ato - de resistência. A linguagem também é um lugar de combate.

(hooks, 1989, p. 28)

James C. Scott afirma, no livro que fez com que nos aproximássemos de forma diferente das lógicas ocultas dos grupos subalternos:

Primeiro, o discurso oculto é um produto social e, portanto, resultado das relações de poder entre subordinados. Segundo: como a cultura popular, o discurso oculto não existe na forma de pensamento puro; existe somente na medida em que é praticado, articulado, manifestado e disseminado dentro dos espaços sociais marginais. Terceiro: os espaços sociais nos quais cresce o discurso oculto são por si mesmos uma conquista da resistência, que se ganha e se defende nas entranhas do poder. (Scott, 2003, p. 175, tradução nossa)

O que Angela Davis nos apresenta nesse texto é um dos espaços sociais onde crescia o discurso oculto das mulheres negras, aquele de onde respondiam, resistiam às construções ideológicas que, no poder, moldavam sua sexualidade como primitiva e exótica. Esse espaço, que Patricia Hills Collins incluiu em uma categoria mais ampla como espaço social e cultural, é o das cantoras negras de blues da primeira parte do século XX. Angela Davis não é a primeira nem a única entre as feministas negras que explorou esse espaço. As cantoras de blues exerceram um forte fascínio nas feministas negras, sobretudo estadunidenses, já desde os primeiros textos literários. ${ }^{8}$ No entanto,

8 Ver, entre outras, Toni Code Bambara, Gayl Jones, Sherley Anne Williams, Alice Walker, Mary Helen Washington, Toni Morrison, Alexis De Veaux e Jessica Hagedorn. Nos anos 8o do século XX iniciam as explorações feministas do blues com os trabalhos de Rosseta Reitz, Sandra Leib e Daphne Duval Harrison. 
foi outra feminista da diáspora negra, Hazel Carby, quem introduziu as cantoras de blues nos primeiros vinte anos do século XX como as autênticas representantes da cultura popular. Fez isso em um texto no qual enfrentou as diferentes visões da sexualidade das mulheres negras que se espelhavam nas escritas das intelectuais e escritoras da classe média negra e as que apareciam nas letras, nas vidas e nos movimentos das cantoras de blues. Nelas aparecem as contradições nas quais são confrontadas as imagens estereotipadas que o discurso hegemônico concebe sobre as mulheres negras. Entretanto, cada grupo o enfrenta de uma maneira diferente. Enquanto nos textos literários são assumidas as categorias do discurso hegemônico que definem a sexualidade feminina negra como primitiva e exótica e são buscadas vias de redenção na negação do desejo e na repressão da sexualidade, ${ }^{9}$ as mulheres do blues, como as grandes "Ma" Rainey ou Bessie Smith, desafiam o patriarcado com maior liberdade. Criam um "discurso" que articula luta cultural e política sobre as relações sexuais; uma luta que se posiciona diretamente contra a objetificação da sexualidade das mulheres em uma ordem patriarcal, mas que ao mesmo tempo reclama os corpos das mulheres como sujeitos sensuais e sexuais. Carby outorga a essas mulheres o papel de intelectuais orgânicas, no sentido gramsciano do termo. Não somente faziam parte da comunidade sujeito de sua música, como também eram produto do movimento rural-urbano. Carby analisa a partir desse contexto social as migrações rurais-urbanas (sul-norte), a forma como as atuações e os discos refletiram e marcaram as relações sexuais dentro da comunidade negra, assim como o terreno cultural no qual as diferenças sexuais eram disputadas e redefinidas (Carby, 1986).

Angela Davis parte do trabalho de Carby e de sua obra anterior Mulheres, raça e classe para buscar no blues feminino dos anos 1920 os rastros e rostos de uma tradição secreta de um feminismo de classe trabalhadora, que coexiste junto a uma tradição de classe média negra, mas cujos códigos e formas de expressão eram completamente distintos. Frente à obra (escrita) das intelectuais do feminismo negro, referentes tradicionais do movimento feminista negro, os textos (não escritos) do blues feminino aparecem como o veículo de expressão das ideias produzidas nas e pelas mulheres pobres de classe trabalhadora, aquelas que nunca poderiam acessar os textos escritos e aquelas que não se reconhecem - salvo nas categorias de exclusão - em suas imagens que são projetadas tanto pelo sistema hegemônico (branco) quanto pela classe média negra. Nesse sentido, o blues é o herdeiro das canções de trabalho e dos rituais na época da escravidão. Músicas que conseguiam traduzir os desejos e os lamentos da população negra em uma expressão de caráter coletivo, em um discurso que, na medida em que era inacessível para os grupos dominantes, funcionava como uma expressão comunitária da experiência de ser negro. No entanto, enquanto a música da escravidão - ambas, a secular e a religiosa - era a quintessência da música coletiva no sentido de que era coletivamente criada e refletia o desejo da comunidade pela liberdade, o blues - a forma musical afroestadunidense predominante no período pós-escravidão - articulou um novo valor

9 Hazel Carby analisa as obras de Zora Neale Hurston, Jessie Fauset e Nella Larsen. 
das diferentes aspirações e necessidades emocionais. $\mathrm{O}$ nascimento do blues era uma prova estética de novas realidades psicossociais entre a população negra. Diante dos referentes coletivos do período anterior, foram incorporadas duas características do sistema hegemônico: a individualidade e a diferenciação sexual. Angela Davis já havia argumentado em trabalhos anteriores que a população negra havia conseguido durante a escravidão a façanha prodigiosa de transformar a igualdade negativa que emanava do fato de sofrer a mesma opressão como escravizados ${ }^{10}$ de forma positiva: a igualdade nas relações sociais (Davis, 2016). Nesse texto, ela introduz dois dos aspectos que, com a emancipação, transformaram radicalmente a vida da população afro-estadunidense: a viagem e a exploração livre da sexualidade. E demonstra como esse duplo exercício da liberdade individual está presente em todas as composições de blues da época, tanto nas dos homens quanto nas das mulheres. Embora apareça de distintas formas, isso ocorre de tal maneira que essas duplas vivências apontavam trajetórias genericamente diferenciadas na população negra. Os homens e as mulheres do blues compartilhavam a linguagem e a experiência do trem e da sexualidade. No entanto, havia significados diferentes para cada um.

O discurso hegemônico - que estava também representado nas vozes masculinas - diferenciava entre quem viajava (os homens) e quem sentia o desamparo do abandono (as mulheres), como expressava uma das canções de Peetie Wheststraw trazida por Angela Davis no texto que apresentamos:

When a woman gets the blues, she hangs her head and cries.

When a man gets the blues, he flags a freight train and rides. ${ }^{n}$

As cantoras negras de blues resistiram em exprimir em suas letras trajetórias femininas marcadas pela resignação e pela impotência. Pelo contrário, suas letras estavam cheias de referências sobre a independência feminina, o controle dos seus desejos e o exercício livre de sua própria sexualidade. Não eram somente as letras. Suas trajetórias de vida estavam matizadas por esses cenários construídos à margem da moral dominante; cenários que se transformaram, finalmente, em referentes para as mulheres pobres ou de classe operária que o discurso hegemônico colocava no papel de vítimas ou no estereótipo de jezzabel, mulheres dominadas por seu apetite sexual e vítimas de seus excessos. Porque era assim que se traduzia, na percepção da moral dominante, a recém-adquirida (e praticada) liberdade sexual das mulheres negras. O que Angela Davis propõe nesse sugestivo texto é que cantoras de blues como "Ma" Rainer ou Bessie Smith, em cujas letras ela desentranha as

10 O patriarcado branco havia anulado a possibilidade da existência de um patriarcado negro entre os escravizados: "Assim como as mulheres negras dificilmente eram 'mulheres' no sentido corrente do termo, o sistema escravista desencorajava a supremacia masculina dos homens negros." (Davis, 2016, p. 26).

11 "Quando uma mulher fica deprimida, inclina a cabeça e chora/Quando um homem fica deprimido, toma um trem de mercadorias e vai embora” (Tradução nossa). 
origens do pensamento feminista negro, desempenharam nos anos 1920 o papel de intelectuais no sentido que Collins confere às feministas negras: aquelas mulheres que são capazes de traduzir as necessidades de outras mulheres em um discurso que permite e/ou possibilita seu empoderamento. As cantoras de blues tinham essa capacidade porque, como dizia Carby, elas mesmas faziam parte desse grupo, por isso eram capazes de entender as lógicas a partir do lugar de atuação, sentimento e sofrimento das mulheres negras de classe operária. A partir daí, com um código que compartilhavam e que, com o tempo, as distanciava dos grupos dominantes, elas eram capazes de estabelecer uma espécie de comunhão através das letras de suas canções como também por sua maneira de estar, de se deslocar, de chegar até elas. Aquilo que na perspectiva hegemônica da sociedade era visto como excesso, no blues era compreendido pela capacidade de agência. As mulheres negras não estavam dominadas por seu apetite sexual; escolhiam praticar sua sexualidade livremente, à margem do imaginário do amor romântico ligado ao matrimônio imposto pela sociedade branca. O blues feminino funcionava, nesse sentido, como linguagem de resistência, capaz de articular em um discurso comum os interesses coletivos de um grupo subjugado.

\section{Redefinir o conceito de família: o valor do parentesco. Um diálogo com Carol Stack}

Confesso que quando li pela primeira vez All our Kin, a maravilhosa monografia na qual se baseia o texto que apresentamos nesta antologia, pensei que Carol Stack era negra. Depois soube que ela mesma se sentiu e se percebeu assim nos três anos que morou no gueto (Stack, 1972). Já existiam pesquisas pioneiras nas comunidades negras como a que Du Bois (1899) realizou no começo do século, mas desde os anos 1930 as aproximações haviam sido realizadas a partir de dados quantitativos. Algumas, inclusive, foram especialmente tóxicas para a imagem da comunidade negra nos Estados Unidos. Carol Stack faz referência àquela que foi, sem dúvidas, a mais influente política e socialmente: o Informe Moynihan (1965).

Trata-se de um texto de assessoramento político, redatado pelo sociólogo que lhe dá nome, no qual é descrita e diagnosticada a "família negra" a partir de critérios elaborados sobre a base de um modelo de família nuclear que universaliza o modelo de família de classe média branca estadunidense. Tomando como referente de normalidade o matrimônio heterossexual, aponta como anomalias as práticas da família negra: "Um quarto dos casamentos estão desfeitos, aproximadamente um quarto dos nascimentos são ilegítimos; pelo menos um quarto das famílias tinha como chefe uma mulher", características essas que, segundo o autor, permitem falar da "desintegração da família negra" e derivar como consequências de tal ruptura "a crescente dependência das políticas assistenciais públicas" e o empobrecimento da comunidade negra. O Informe Moynihan ia mais além. Destacava que a causa 
para essa situação tinha raízes históricas, localizadas na prática escravista e nos posteriores deslocamentos massivos em direção às cidades. O diagnóstico? Uma espécie de patologia da família negra que tinha, inclusive, um nome: matriarcado.

O efeito desse relatório na comunidade negra foi muito daninho. As imagens estereotipadas das mulheres negras as distanciavam do ideal de feminilidade que acompanhava tradicionalmente a família "ideal” e que se apoiava na imagem de uma determinada mulher que possuía as quatro virtudes cardinais: piedade, pureza, submissão e domesticidade (Collins, 200ob, p. 72). Através desses estereótipos femininos, demonstrava-se a desestruturação das famílias negras e se explicava, a partir dela, os índices de pobreza, de marginalidade e inclusive de violência entre as comunidades negras.

Pensadores, políticos e também cientistas sociais se apoiaram no Informe para caracterizar uma "subclasse" [underclass] e formular, tomando-o como base empírica, discursos, programas e medidas políticas. Uma das ideias de maior ressonância dentro da política de "ajuda assistencial" é a que tende a identificar as mulheres negras, chefes de família monoparentais, como as principais preceptoras do salário social. Isso gerou um novo estereótipo, que Collins (200ob) define como "a mãe dos serviços sociais" [Welfare Mother], uma imagem que define a mulher como alguém com pouco interesse em ascender e manter um emprego e que, em troca, engravida com frequência com o fim de conseguir mais dinheiro dos cofres do Estado. Ao mesmo tempo, é retratada como uma mãe incapaz de socializar seus filhos nos valores cívicos e de impor a eles padrões normativos para que valorizem e aceitem a ética do trabalho, o que acaba perpetuando a situação de pobreza que parece envolver toda a família. Quer dizer, são responsabilizados pela situação crônica de pobreza nas margens internas do gueto negro os indivíduos que sofrem tudo isso, além das próprias mulheres.

O trabalho de Carol Stack foi um dos primeiros em romper com essa imagem. Anos antes, outro antropólogo, Elliot Liebow, havia indagado as lógicas internas do gueto através dos olhos, olhares e vozes dos homens negros. Seu estudo, Tally's Corner (1967), foi uma das primeiras respostas da antropologia ao Informe Moynihan. No entanto, esse olhar penetrante, na medida em que se centrava quase que exclusivamente nos homens e considerava de forma periférica as famílias, não atingiu o coração da comunidade. Carol Stack, por outro lado, ao situar as mulheres no centro e dar relevância ao seu ponto de vista, pôs o foco nos lares - que se formavam ao redor das mulheres - e nas redes que elas articulavam. A partir desse emaranhado que ela desembaraça, passam a ser visíveis as lógicas comunitárias que sustentam as redes. Atendendo às vozes das mulheres negras lutando para criar seus filhos no gueto, Stack mostrou que as condutas que a sociedade dominante condenava como patológicas eram realmente estratégias das próprias mulheres para manter a coesão e satisfazer suas necessidades econômicas.

O trabalho de Carol Stack teve um rápido e amplo reconhecimento no campo disciplinar da antropologia social como exemplo de estudo etnográfico sobre a pobreza e a desigualdade social. Por sua vez, o feminismo negro havia retomado seus 
aportes etnográficos como base para a reconceitualização da família e da comunidade. "Colocando as mulheres afro-estadunidenses no centro da análise" - afirma Hill Collins (200ob) -, "Stack não somente revela que são necessárias mais informações sobre as experiências das mulheres como também questiona as perspectivas eurocêntricas e masculinas sobre a família". Ao estudar o papel das mulheres negras na luta e na sobrevivência do grupo, revela-se um modelo (afrocêntrico) de comunidade que, em contraste com a definição de comunidade implícita no modelo de mercado, estruturada fundamentalmente pela competição e pela dominação, é construída sobre as conexões, o cuidado e a responsabilidade pessoal (hooks, 1989).

Entendo que esta colaboração justificaria a inclusão de Carol Stack em qualquer antologia de feminismo negro. No entanto, esta compilação é uma das primeiras a fazer isso. Talvez seja porque, como ela mesma afirmou, apesar de, nos anos em que viveu no gueto, ter esquecido em muitas ocasiões a cor da sua pele, nunca teve a ilusão de ser uma habitante daquele lugar (Duneier, 2007). Teve a suficiente capacidade para entender as outras mulheres com seus códigos e, ao mesmo tempo, ser consciente da diferença entre ela e seus sujeitos. O trabalho de Carol Stack é um trabalho comprometido que se encaixaria bem na trilogia com a qual Hill Collins sintetizava o papel das intelectuais negras (conhecimento/consciência/ empoderamento). Poucos trabalhos teóricos atingiram o nível de penetração nas lógicas da comunidade negra como a aproximação etnográfica de Carol Stack; a tal ponto que Gilroy e hooks demandavam um trabalho com essa capacidade de introspecção para descobrir e mostrar como funciona atualmente a comunidade negra em contextos marginais (Gilroy, 1993). A única coisa que diferencia Carol Stack de outras autoras que apresentamos nesta antologia é a sua desvinculação com o movimento político; efetivamente, não se pode dizer que Carol Stack seja uma feminista negra. No entanto, sua obra contribuiu de forma substancial para a criação do pensamento negro e isso também merece um reconhecimento.

\section{Segunda Onda do pensamento feminista negro. Diáspora e estudos culturais.}

Ao colocar o racismo no epicentro da desigualdade das mulheres negras, o feminismo negro estadunidense abriu a porta para outros feminismos. No contexto europeu, o feminismo negro britânico tomou a dianteira. Frente à vivência da escravidão, vital no discurso afro-americano, as britânicas negras incorporaram situações e/ou vivências do pós-colonialismo, as migrações e os deslocamentos. Fizeram-no partindo de outra categoria de "negro". Avtar Brah o explica da seguinte forma:

Na medida em que mulheres negras compreendiam uma categoria altamente diferenciada em termos de classe, etnia e 
religião, e incluíam mulheres que tinham migrado da África, do subcontinente asiático e do Caribe, tanto como aquelas nascidas na Grã-Bretanha, o negro do "feminismo negro" inscrevia uma multiplicidade de experiências, ainda que articulasse uma posição particular de sujeito feminista. Além disso, ao trazer para o primeiro plano uma ampla gama de experiências diaspóricas em sua especificidade tanto local quanto global, o feminismo negro representava a vida negra em toda sua plenitude, criatividade e complexidade (Brah, 2006, p. 357).

Ligadas ao movimento intelectual britânico da New Left [Nova Esquerda] e com vínculos teóricos com a diáspora negra, as feministas negras britânicas construíram um discurso identitário frente às posições da esquerda e do feminismo branco. As autoras que apresentamos nesta antologia, Hazel Carby e Pratibha Parmar são, nesse sentido, representativas de um movimento que teve seu centro de operações no grupo Raça e Política do Center for Contemporary Cultural Studies (CCCS) da Universidade de Birmingham.

O CCCS foi criado em 1964 dentro do que foi o movimento da New Left. Esse movimento aglutinou membros relevantes da intelectualidade pós-colonial e anticolonialistas sem espaço nem acolhimento dentro das instituições dominantes da esquerda britânica. Um deles, talvez hoje o mais canonizado de seus pais fundadores, é o sociólogo e crítico Stuart Hall (Morley; Chen, 1996), talvez porque se encontre entre a primeira geração, mais centrada nas tradições e resistências do proletariado britânico (representada nas obras de Hoggart, Williams ou E. P. Thomson), e a segunda, que incorpora como questões centrais a "raça" e o feminismo. De fato, quando Hazel V. Carby e Pratibha Parmar, junto com Valerie Amos ou Paul Gilroy, se incorporaram à Universidade de Birmingham, o CCCS era liderado por Stuart Hall e já havia iniciado o que o próprio Hall qualificaria como a virada da classe para a "raça" e o gênero, para o que, sem dúvida nenhuma, contribuíram os e as integrantes do grupo Raça e Política. Tanto é assim que o texto de Carby que selecionamos, White Women Listen! Black Feminism and the Boundaries of Sisterhood, na ocasião um dos referenciais teóricos do feminismo negro, foi publicado pela primeira vez em um dos livros de referência dos Estudos Culturais, The Empire Strikes Back (1981); neste volume também participou Pratibha Parmar com o capítulo Gender, Race and Class. Asian Women in Resistence. Com o trabalho de ambas, ao qual se deveria somar também o texto que Pratibha Pramar escreveu junto com Valerie Amos (1984), o gênero foi incorporado ao CCCS partindo da/na intersecção com a "raça", distinguindo-se e diferenciando-se da primeira onda feminista, completamente alheia à questão racial (Brundson, 1996).

Segundo aponta Grossberg, o projeto dos Estudos Culturais era construir uma história política do presente e fazer isso de uma forma particular, de uma maneira contextualista. Ele pretende evitar reproduzir os universalismos que contribuíram como prática dominante de produção de conhecimento - para forjar certas relações 
de dominação, desigualdade e sofrimento; e busca práticas capazes de abranger a complexidade e a contingência, assim como evitar qualquer espécie de reducionismo (Grossberg, 2006). O trabalho de Carby e de Parmar se desenvolve dentro dessas tendências. No caso de Hazel Carby, ademais, deve-se apontar a estreita relação que estabelece intelectualmente com Paul Gilroy, o outro grande teórico da diáspora negra no CCCS. Como ele, Carby move-se entre dois pilares teóricos: a tradição póscolonial dos Estudos Culturais britânicos, personificada na figura de Stuart Hall, e os pensadores e intelectuais afro-estadunidenses que tentaram recuperar a tradição histórica e literária da comunidade negra, oculta pelo véu do racismo na sociedade estadunidenses. Gilroy incorpora, além disso, o conceito de Atlântico Negro dos afrocaribenhos, britânicos e americanos. Em seu livro The Black Atlantic ${ }^{12}$ ele apresenta uma cultura diaspórica negra diversa que transcende os limites das identidades nacionais e/ou étnicas. Este mapa/narrativa coloca em primeiro lugar as histórias de cruzamento, migração, interconexão e viagem. Partindo desse ponto, dessas zonas de contato, reescreve a história do Atlântico Negro e a de algumas de suas figuras mais emblemáticas.

A produção teórica de Hazel V. Carby discorre também nesse território amplo, de cruzamentos, interconexões e viagens, que é o Atlântico Negro, e contribuiu substancialmente para a geração do pensamento negro. ${ }^{13} \mathrm{O}$ texto apresentado nesta antologia, White Women Listen! Black Feminism and the Boundaries of Sisterhood (1982), se enquadra nesse tipo de produção gerada no CCCS nos anos 1980, trabalho intelectual de alto nível, mas com evidente vocação de transformação política. Carby também queria contribuir para a transformação política do feminismo. Em primeiro lugar, denunciou os vazios, as lacunas existentes, que apareciam no movimento hegemônico desde os anos 1970. Posicionou-se junto às feministas negras que, em ambos os lados do Atlântico, partindo de diferentes posições, e por meio de distintas estratégias, exigiam que se reconhecesse a existência do racismo como um traço estrutural de suas relações com as feministas brancas. Em segundo lugar, criticou e questionou supostos conceitos universais centrais na teoria feminista, que demonstrou problemáticos ao serem aplicados nas vidas das mulheres negras, como "família", "patriarcado" e "reprodução". Carby assentava, assim, as bases para uma sistematização do conhecimento construído pelas feministas negras em contextos afro-estadunidenses, asiáticos e africanos. Em terceiro lugar, ela abriu uma via para uma possível interpretação do feminismo por diferentes grupos de mulheres a partir de posições igualitárias. Para isso, são necessários conceitos que permitam especificidade e, ao mesmo tempo, provenham de pontos de referência transcultural. Carby aposta no conceito de "sistemas sexo-gênero" de Gayle Rubin (1975), que, por um lado, oferece a oportunidade de ser histórica e culturalmente específico e, por outro, indica a posição de autonomia relativa da esfera sexual, possibilitando que a subordinação das mulheres seja vista como um "produto das relações que organizam

12 No Brasil: GILROY, P. O Atlântico Negro: Modernidade e Dupla Consciência. Tradução de Cid Knipel Moreira. São Paulo: Editora 34, 2001.

13 Ver, por exemplo, Carby $(1987,1998,1999)$. 
e produzem o sexo e o gênero". Partindo desse marco teórico, qualquer relação familiar deve ser entendida e explicada pela lógica própria de um sistema sexogênero específico, e qualquer padrão de subordinação deve ser historicizado, em vez de depreciado como um produto de uma estrutura familiar patológica.

A publicação de White Woman Listen! alimentou um corpus teórico crítico com o feminismo branco por parte de feministas negras britânicas - incluindo o volume que a revista Feminist Review dedicou ao tema em 1984, Many Voices, One Chant: Black Feminist Perspectives - que sublinha as teorias e práticas etnocêntricas do feminismo branco. ${ }^{14}$ Isso gerou, entre as feministas socialistas, um questionamento de seus pressupostos teóricos. $\mathrm{O}$ artigo Ethnocentrism and SocialistFeminist Theory de Barret e McIntosh (1985) sintetiza essa resposta, reflexo, por sua vez, das contradições do próprio movimento feminista na Inglaterra. De um lado, os autores reconheciam as limitações do conceito de patriarcado como uma dominação masculina invariável, independente da classe e do racismo; mas, de outro, não foram capazes de ver que as estruturas de classe, racismo, gênero e sexualidade não podem ser tratadas como "variáveis independentes" porque a opressão de cada uma está inscrita dentro da outra - é constituída por e constitutiva das outras. O problema, que também se percebe no artigo, é - como apontaria Avtar Brah (2011) - a tendência a tratar as questões de desigualdade centrando-se nas vítimas: "Os debates sobre o feminismo e o racismo frequentemente se centram na opressão das mulheres negras ao invés de explorarem como o gênero tanto de mulheres brancas como de mulheres negras se constrói por meio da classe e do racismo". Kum-kum Bhavnani e Margaret Coulson também reagiram àquele texto:

O racismo atua de uma maneira que situa as diferentes mulheres em diferentes relações com as estruturas de poder e de autoridade na sociedade [...]. Não é que apenas haja diferenças entre os distintos grupos de mulheres, mas sim que essas diferenças são, frequentemente, cenário de um conflito de interesses (Bhavnani, Coulson, 2004).

O texto de Pratibha Parmar, Black Feminism: The Politics of Articulation (1990), escrito posteriormente a esta efervescência teórica e política do feminismo negro britânico, situa-se já em outro momento, quando começa a tornar-se visível sua "desintegração". O trabalho que apresentamos abarca, com extraordinária lucidez, este momento de incerteza para o próprio movimento. Mas não se limita a isso. Partindo da análise e do diagnóstico da situação - a dissolução de um pensamento (e ação) coletivo na luta pelo reconhecimento de (diversas e sobrepostas) identidades oprimidas -, inicia um novo itinerário para, a partir desse espaço, dar outro salto em direção à busca de um novo caminho, de um "novo tipo de sonhos".

14 Ver, entre outras, Amos, Parmar (1984), Parmar, Miza (1981), Brah, Minhas (1985), Lewis, Parmar (1983), Bryan, Dadzie, Scafe (1985), Visram (1989), Bhachu (1988), Phoenis (1988), Parmar (1990), Brah (2011). 
Pratibha Pramar incorpora neste texto diferentes formas expressivas. Começa em um formato mais acadêmico, formulando o que sem dúvida é a força e a fraqueza do feminismo negro britânico, isto é, a articulação de múltiplas autoidentidades (as mulheres britânicas negras são parte de muitas diásporas) com uma consciência coletiva que fortaleça mulheres que, como negras, como feministas, como lésbicas, habitam posições de marginalidade e resistência. O feminismo negro conseguiu realizar isso na década de 1980, mas as políticas identitárias diluíram esta potência ao falar de "experiências subjetivas autênticas". O problema que Pramar indica para o feminismo negro britânico, mas que não se limita a este movimento, é que a releitura em termos de identidade de subjetividades compartilhadas em contextos de opressão acaba sendo colocada como uma hierarquia de opressões e que, portanto, enfatiza a acumulação de uma coleção de identidades oprimidas. Dessa maneira, desvia-se o olhar de metas que contribuam realmente para a mudança social.

Pramar se propõe a reorientar esse olhar. E é aqui que incorpora e ensaia novas formas estilísticas. Primeiro, agregando novas vozes a seu discurso e, depois, por meio de imagens. É muito sugestivo o uso que ela faz do texto dialogado. Como referente intelectual inclui a poeta, artista e pensadora June Jordan. Com ela pensa, constrói pensamento, alinhava estratégias de ação. Mostra, com as imagens, como se pode gerar um novo discurso, um discurso visual que explore a complexidade e harmonize as diferenças. Abre caminho para que, a partir da fotografia, as políticas de representação convivam com as estratégias de desconstrução e decodificação e gerem movimentos de reconstrução e recodificação.

\section{Novas narrativas. Discurso pós-colonial e identidades diaspóricas}

O debate que Pratibha Pramar deixou aberto em Black Feminism: The Politics of Articulation está no centro das novas contribuições que as experiências pós-coloniais e diaspóricas dão ao feminismo negro. As categorias raciais fechadas e binárias sobre as quais se construiu o pensamento feminista negro são problemáticas em tempos pós-modernos. A questão da identidade - dizia Pramar - adquiriu um peso colossal para aquelas de nós que somos migrantes pós-coloniais habitando histórias de diáspora. Mas, como se define hoje a identidade? Stuart Hall (2000), o "intelectual da diáspora”, como foi denominado por Kuan-Hsing Chen (2011), discute o tópico nos seguintes termos:

Não estou sugerindo que todas essas conotações devam ser importadas em bloco e sem tradução para o nosso pensamento sobre a "identidade"; elas são citadas aqui para indicar os novos significados que o termo está agora recebendo. O conceito de identidade aqui desenvolvido não é, portanto, um conceito essencialista, mas um conceito estratégico e posicional. Isto é, de forma diretamente contrária àquilo que parece ser sua carreira 
semântica oficial, esta concepção de identidade não assinala aquele núcleo estável do eu que passa, do início ao fim, sem qualquer mudança, por todas as vicissitudes da história. Esta concepção não tem como referência aquele segmento do eu que permanece, sempre e já, "o mesmo", idêntico a si mesmo ao longo do tempo. Ela tampouco se refere, se pensarmos agora na questão da identidade cultural, àquele "eu coletivo ou verdadeiro que se esconde dentro de muitos outros eus - mais superficiais ou mais artificialmente impostos - que um povo, com uma história e uma ancestralidade partilhadas, mantém em comum" (Hall, 1990). [...] Essa concepção aceita que as identidades não são nunca unificadas; que elas são, na modernidade tardia, cada vez mais fragmentadas e fraturadas; que elas não são, nunca, singulares, mas multiplamente construídas ao longo de discursos, práticas e posições que podem se cruzar ou ser antagônicas. As identidades estão sujeitas a uma historicização radical, estando constantemente em processo de mudança e transformação. [...] Elas têm a ver, entretanto, com a questão da utilização dos recursos da história, da linguagem e da cultura para a produção não daquilo que nós somos, mas daquilo no qual nos tornamos. Têm a ver não tanto com as questões "quem nós somos" ou "de onde nós viemos", mas muito mais com as questões "quem nós podemos nos tornar", "como nós temos sido representados" e "como essa representação afeta a forma como nós podemos nos representar a nós próprios” (Hall, 2000, p. 107-109).

Nofeminismonegro, quem colocou em questãoasidentidades essencializadoras foram mulheres que, partindo de posições diaspóricas e pós-coloniais, sentiram o vazio da não representação. Foram também elas que, demandando um reconhecimento à margem das categorias de representação impostas - dos grupos dominantes e daqueles que o sistema hegemônico reconhece (e se reconhecem) como dominados -, se autorrepresentaram, criando seu próprio não espaço, como diria Ifekwunigwe, ou seus espaços de (des)localização, como diria Magdalene Ang-Lygate; territórios in-explorados onde residem os significados variáveis da diáspora. Trinh T. Minh-ha (1986) utiliza este intangível espaço intermediário e desenvolve sua teoria do "outro inapropriado / inapropriável” como uma imagem da mulher pós-colonial, aquela que resiste às definições da outridade impostas e insiste em definir a diferença partindo de sua própria perspectiva. Posição que faz dela uma pessoa incômoda, duplamente problemática.

Em When the Mirror Speaks: The Poetics and Problematics of Identity Construction for Métisse Women in Bristol, Jayne Ifekwunigwe (1999) evidencia a dureza do território no qual habitam as mulheres mestiças, começando pelo uso de uma categoria, métisse, que não tem fácil acomodação na língua inglesa. Ifekwunigwe apresenta seis relatos de mulheres que se enfrentam com a tensão de serem mestiças e se transformarem em negras. E o faz por meio de suas narrativas, que se transformam, 
simultaneamente, em recurso metodológico e espaço identitário. No texto, a identidade aparece como relato, ao mesmo tempo real e fictício, vivido e construído. As identidades se constroem nas representações e não fora delas, dizia Stuart Hall. E Ifekwunigwe entra em cheio no espaço - teatral, dramático - das representações. Suas seis narradoras (às quais ela dá o nome de griottes - griôs -, relacionandoas às tradições africanas) representam um papel, representam-se através desse jogo que a linguagem oferece em um cenário duplo, no domínio privado (onde elas se constroem identitariamente em um jogo complexo de identidades poliétnicas) e no público, onde lhes é devolvida a imagem de uma identidade essencializada. Através do narrativo, emerge a construção que as mestiças fazem de si mesmas e as contradições do discurso racializado; assumindo a visibilidade em seu papel como griottes, essas mestiças narram o que é "real" (como vivido) e o que é "ficção" (como construído) no discurso racial (Mirza, 1997).

Magdalene Ang-Lygate em Charting the spaces of (un)location. On theorizing diaspora (1997) também se situa nesse espaço problemático no qual se evidenciam as contradições dos sujeitos pós-coloniais. A vivência da pós-colonialidade de AngLygate não é a de uma mestiça, mas de uma mulher que construiu sua identidade com os referentes do colonizador. Seu nome, seu idioma, sua cultura são inglesas; mas nenhum desses pontos faz dela uma cidadã britânica. Migrante não é uma categoria transitória na Inglaterra: não há uma categoria british-born immigrant na qual possam se reconhecer as migrantes pós-coloniais que vivem no país. Existe a categoria "negra", na qual a sociedade britânica insere todas as mulheres que não são brancas. Mas nem Ang-Lygate nem as mulheres que aparecem como sujeitos em suas pesquisas - migrantes que como ela vêm da China, Malásia, Filipinas - se encaixam nesta categoria. Talvez por essa difícil fixação em uma identidade racial que não compartilha (e da qual é excluída), ela percebe com maior agudeza as limitações dessa categorização na qual, por outro lado, sentem-se tão cômodos aqueles grupos entre os quais Ang-Lygate inclui o feminismo negro - que usam o critério racial como estratégia política. Como ela expõe no texto que apresentamos: "O que realmente me preocupa é que, quando se joga esse tipo de jogo, somos cúmplices de uma estrutura que se construiu desde o princípio sobre um dualismo binário que inevitavelmente desfaz a possibilidade de diferença” (Ang-Lygate, 2012, p. 297-298, tradução nossa).

Como ocorria com a mestiça, a mulher pós-colonial que é Ang-Lygate questiona essas formas de outridade reconhecidas como apropriadas e toleradas, e reivindica outras formas de outridade que, ao sair dos confins entre os quais foram definidos os limites identitários dominantes, são percebidas como subversivas e, como tais, rechaçadas ou reprimidas. Como fazia Ifekwunigwe, Ang-Lygate também explora, dessa posição, o conceito de identidade diaspórica, sobre a qual Stuart Hall teorizou de forma tão acertada, em relação às migrantes chinesas, que são sujeitos de sua pesquisa. Desde esse conceito - que entende as identidades "fragmentadas e fraturadas; [...] multiplamente construídas ao longo de discursos, práticas e posições que podem se cruzar ou ser antagônicas" (Hall, 200o, p. 108) - ela entende e explica esses "espaços de silêncio", onde se situam essas outras formas de outridade não 
reconhecidas pelos discursos hegemônicos, experiências de diáspora. Lendo-as como tal, conseguimos visibilizá-las, "para reconhecer finalmente que nossa própria invisibilidade não é estado natural de ninguém" (Ang-Lygate, 2012, p. 311, tradução nossa).

\section{E para terminar}

Até aqui vai meu diálogo pessoal com as autoras selecionadas nesta antologia.

A partir de agora, apenas suas vozes. São seus textos que realmente convidam para um diálogo.

Pessoalmente, sinto-me feliz de estar em tão grata companhia.

\section{Referências}

ÁLVAREZ, Silvia. "Diferencia y teoría femenista”. In: BELTRÁN, María Elena., MAQUEIRA, Virginia (Orgs.) Feminismos. Debates teóricos contemporáneos. Madrid: Alianza Editorial, 2001.

AMOS, Valerie; PARMAR, Pratibha. "Many Voices, One Chant: Black Feminist Perspectives". Feminist Review, n. 17, 1984.

ANG-LYGATE, Magdalene. "Charting the spaces of (un)location. On theorizing diaspora”. In: MIRZA, Heidi Safia. Black British Feminism. A Reader. London, New York: Routledge, 1997.

ANG-LYGATE, Magdalene. “Trazar los espacios de la deslocalización. De la teorización de la diáspora”. In: JABARDO, Mercedes (Org.). Feminismos negros. Una antología. Madrid: Traficantes de sueños, 2012. Traducción de Esperanza Mojica.

BARRET, Michèle; MCINTOSH, Mary. "Ethnocentrism and Socialist-Feminist Theory". Feminist Review, n. 20, p. 23-47, 1985.

BHACHU, Parminder. "Apni Marzi Kardhi. Home and Work: Sikh Women in Britain”. In:WESTWOOD, Sallie; BHACHU, Parminder(Orgs.). Enterprising Women: Ethnicity, Economy and Gender Relations. Londres: Routledge, 1988.

BHAVNANI, Kum-kum; COULSON, Margaret. "Transformar el feminismo socialista. El reto del racismo". In: hooks et al. Otras inapropiables. Madrid: Traficantes de Sueños, p. 54, 2004. 
BRAH, Avtar; MINHAS, R. "Structural Racism and Cultural Difference: Schooling for Asian Girls”. In: WEINER, Gaby. (Org.). Just a Bunch of Girls. Milton Keynes: Open University Press, 1985.

BRAH, A. "Diferença, diversidade, diferenciação”. Cadernos Pagu. Campinas, n. 26, p. 329-376, Jun, p. 357, 2006.

BRAH, A. Cartografías de la diáspora. Madrid: Traficantes de sueños, 2011.

BRUNSDON, Charlotte. "A Thief in the Night. Stories of Feminism in the 1970s at CCCS”. In: MORLEY, David; CHEN, Kuan-Hsing (Orgs.). Stuart Hall. Critical Dialogues in Cultural Studies. London, New York: Routledge, 1996.

BRYAN, Beverley; DADZIE, Stella; SCAFE, Suzanne. The Heart of the Race. Black Women's Lives in Britain. Londres: Virago, 1985.

CARBY, Hazel. Reconstructing Womanhood: The Emergence of Afro-American Woman Novelist. New York: Oxford University Press, 1987.

“It jus be's dat way sometime: the sexual politics of women's blues". Radical America, v. 20, n. 4, p. 9-24, 1986.

Race Men: The Body of Soul and Race, Nation and Manhood. Cambridge: Harvard University Press, 1998;

. Cultures in Babylon. London: Verso, 1999.

"White Women Listen! Black Feminism and the Boundaries of Sisterhood". In: CENTRE FOR CONTEMPORARY CULTURAL STUDIES. The Empire Strikes Back. Race and Racism in 7os Britain. London: Routledge, 1982.

CHEN, Kuan-Hsing. "Stuart Hall: la formación de un intelectual de la diáspora”. Revista de Occidente, n. 234, p. 95-119, 2011.

CENTRE FOR CONTEMPORARY CULTURAL STUDIES. The Empire Strikes Back. Race and Racism in 70s Britain. London: Routledge, 1982.

COLLINS, Patricia Hill. "Gender, Black Feminism and Black Political Economy”. In: ANNALS OF THE AMERICAN ACADEMY OF POLITICAL AND SOCIAL SCIENCE, n. 568, p. 41-53, $2000 a$.

Black Feminist Thought: Knowledge, Consciousness and the Politics of Empowerment. New York: Routledge, 2ooob. 
DAVIS, Angela. Mulheres, raça e classe [recurso eletrônico]. Tradução de Heci Regina Candiani. São Paulo: Boitempo, 2016.

DU BOIS, William Edward Burghardt. The Philadelphia Negro. Philadelphia: University of Pennsylvania, 1899.

DUNEIER, Mitchell. "On the legacy of Elliot Liebow and Carol Stack: context-driven fieldwork and the nees for continuous ethnography”. Focus, v. 25, n. 1, 2007.

GILROY, Paul. Small Acts. Londres: Serpent's Tail, 1993.

GROSSBERG, Lawrence. "Stuart Hall sobre raza y racismo: estudios culturales y la práctica del contextualismo”. Tabula Rasa, n. 5, p. 47, 2006.

HALL, Stuart. “Quem precisa de identidade?” In: SILVA, T. T. (Org.). Identidade e diferença: A perspectiva dos Estudos Culturais. Petrópolis: Vozes, p. 107-109, 2000.

HARAWAY, Donna. Ciencia, cyborg y mujeres. Madrid: Cátedra Feminismos, 1995.

hooks, bell. Ain't a Woman: Black Women and Feminism. Boston: South End, 1981. . Talking Back. Thinking Feminist. Thinking Black. Boston: South End, 1989. . Feminist theory: From margin to center. Boston: South End, 1984.

HULL, Gloria; BELL SCOTT, Patricia; SMITH, Barbara. All the Women are White, All the Men are Black, But Some of Us Are Brave. New York: The Feminist Press, 1982.

HURTADO, Aída. Relating to privilege: seduction and rejection in the subordination of white women and women of color, Signs, v. 14, n. 4, 1989, p. 833-855.

FEKWUNIGWE, Jayne. (1999) "When the Mirror Speaks: The Poetics and Problematics of Identity Construction for Métisse Women in Bristol”. In: BAROT, Rohit; BRADLEY, Harriet; FENTON, Steve. (Eds.). Ethnicity, Gender and Social Change. London: Palgrave Macmillan, London, 1999.

LEWIS, Gail; PARMAR, Pratibha. Review Article: Black Women Writing. Race and Class, v. 25. n. 2, 1983.

LIEBOW, Elliot. Tally's Corner: a study of negro streetcorner men. Boston, MA: Little Brown, 1967. 
LORDE, Audre. The master's Tools will never dismantle the Master's House. In: . Sister outsider: Essays and Speeches. New York: The Crossing Press Feminist Series, 1984. p. 110-113.

MIRZA, Heidi Safia. Black British Feminism. A Reader. London, New York: Routledge, 1997.

MORLEY, David; CHEN, Kuan-Hsign (Orgs.). Stuart Hall. Critical Dialogues in Cultural Studies. London, New York: Routledge, 1996.

MOYNIHAN. The negro family. The case for national action. Washington, D.C: Departament of Labor, 1965.

O’NEAL, Sandra. Inhibiting Midwives, Usurping Creators: The Struggling Emergence of Black Women in American Fiction. In: LAURENTIS, Teresa de. (Org.). Feminist Studies/Critical Studies. Bloomington: Indiana University Press, 1986.

PARMAR, Pratibha; MIRZA, Nadira. "Growing Angry. Growing Strong”. Spare Rib, n. 1111, 1981.

PARMAR, Pratibha. "Black Feminism: The Politics of Articulation”. In: RUTHERFORD, Jonathan. Identity: Community, Culture, Difference. London: Lawrence \& Wishart, 1990. p. 101-126.

. Black Feminist and the Politics of Articulation. In: RUTHERFORD, Jonathan.

(Org.). Identity, Community, Culture, Difference. Londres: Lawrence and Wishart, 1990.

PHOENIX, Ann. "Narrow Definitions of Culture: The Case of Early Motherhood”. In: WESTWOOD, Sallie; BHACHU, Parminder (Orgs.). Enterprising Women: Ethnicity, Economy and Gender Relations. Londres: Routledge, 1988.

RITZER, G. Teoría sociológica moderna. Madrid: McGraw Hill, 2003.

RITZER, G. Teoría sociológica clássica. Madrid: McGraw Hill, 2005.

RUBIN, Gayle. “The Traffic in Women. Notes on the 'Political Economy' of Sex”. In: REITER, Rayna (Ed.) Toward an Anthropology of Women. New York, Monthly Review Press, 1975 .

SÁNCHEZ, Cristina. “Genealogía de la vindicación”. In: BELTRÁN, María Elena., MAQUEIRA, Virginia (Orgs.) Feminismos. Debates teóricos contemporáneos. Madrid: Alianza Editorial, 2001. 
SCOTT, James. Los dominados y el arte de la resistencia. Tafalla: Txalaparta, 2003.

SPILLERS, Hortense J. "Mama's baby, papa's maybe: an American grammar book", Diacritics, v. 17, n. 2, 1987, p. 65-81.

STACK, C. All our Kin: Strategies for survival in a black community. Nova Iorque: Harper and How, 1972.

THE COMBAHEE RIVER COLLECTIVE. “Uma declaração Negra feminista”. Edição Difusão Herética. Tradução por Apoya Mutua, 2012. Disponível em <https://we.riseup. net/assets/178688/combahee+river+zine.pdf>. Acesso em 15 fev. 2019.

TRINH T. MINH-HA (Ed.). "She, the Inappropiate/d Other. Special Issue on Third World Women”, Discourse, v. 8, 1987.

TRUTH, Sojourner. “E não sou eu uma mulher?” In: Convenção dos Direitos da Mulher, 1852.

VISRAM, Rozina. Ayahs, Lascars and Princess: Indians in Britain 1700-1947. Londres: Pluto, 1989.

WELLS, Ida B. "Horrores sureños: la ley Lynch en todas sus fases". In: JARBADO, Mercedes (Org.). Femenismos negros: Una antologia. Madrid: Traficantes de sueños, 2002. Tradução de Mijo Miquel. 